Working Paper No. 585, 2002

\title{
Social Norms and Welfare State Dynamics
}

by Assar Lindbeck, Sten Nyberg and Jörgen W. Weibull

IUI, The Research Institute of Industrial Economics

P.O. Box 5501

SE-114 85 Stockholm

Sweden 


\title{
Social Norms and Welfare State Dynamics
}

\author{
Assar Lindbeck, Sten Nyberg and Jörgen W. Weibull*
}

November 19, 2002

\begin{abstract}
The paper analyses the interaction between economic incentives and work norms in the context of social insurance. If the work norm is endogenous in the sense that it is weaker when the population share of beneficiaries is higher, then voters will choose less generous benefits than otherwise. We also discuss welfare-state dynamics when there is a time lag in the adjustment of the norm in response to changes in this population share, and show how a temporary shift in the unemployment rate may cause persistence in the number of beneficiaries.
\end{abstract}

JEL Classification: Z13, D19, D64, H31.

Keywords: welfare state, social norms, social insurance.

\section{INTRODUCTION}

It is a commonplace that social insurance, like other insurance schemes, is exposed to moral hazard and, hence, to free riding. One reason is that it is difficult for insurance providers to formulate objective criteria that can discriminate between individuals with bad luck, "deserving beneficiaries", and free riders, "undeserving beneficiaries".

The free-riding problem may be mitigated by lower benefit levels. To some extent, however, this would undermine the very purpose of insurance. Social norms against living off benefits may also mitigate free-riding. One strength of social norms in this respect is that those who enforce the norms are probably close to the individual. Since they are often better informed about the circumstances underlying the benefit dependency than an administrator in the social insurance system they can more easily identify undeserving beneficiaries. Moreover, the enforcement of norms is not constrained by formal rules and procedures which must be followed by publicsector administrators. Individuals who deviate from work norms are discomforted by "shame", emanating from the disapproval of others, or by "guilt" when they internalize the norm. For these reasons, we would expect work norms under certain

*Lindbeck: Institute for International Economic Studies (IIES), Stockholm University, SE-106 91 Stockholm, and Research Institute of Industrial Economics (IUI), Stockholm, Sweden. Phone: +46 8 163078, E-mail: assar.lindbeck@iies.su.se. Nyberg: Department of Economics, Stockholm University, SE-106 91 Stockholm, Sweden. sten.nyberg@ne.su.se. Weibull: Department of Economics, Boston University, 270 Bay State Road, Boston MA 02215, USA. E-mail: weibull@bu.edu. 
circumstances to be quite effective in limiting the number of individuals who intentionally live on benefits. ${ }^{1}$ There are, however, disadvantages and limitations of relying on social norms in this context. One, of course, is that a norm may erode over time in response to a rising number of beneficiaries.

In a previous paper (Lindbeck, Nyberg, Weibull, 1999), LNW for short, we examined the interaction between economic incentives and endogenous work norms in the context of redistributive transfer programs among individuals with different productivities. Here, we instead focus on income insurance and the possibility that some individuals with a relatively high valuation of leisure choose to free ride on the social insurance system. To highlight this issue, we assume that all individuals have the same productivity but differ in their valuation of leisure. Another difference compared to the LNW is that we now emphasize dynamic aspects of the problem. As in the LNW paper, however, we assume that individuals make two type of decisions: an economic decision concerning whether to participate in the labor market or not, and a political decision as a voter concerning the generosity of the benefit program. As has been shown before, (for example in LNW), endogenous norms may generate multiple equilibria in economic decisions.

We focus primarily on the case where those who participate in the labor market constitute a majority of the population and we examine their voting with respect to the generosity of the social insurance system. One question is to determine the degree of generosity in social insurance systems that will be chosen by a majority of voters and how this decision is affected by the presence of social norms. Another question relates to the possibility that social norms exhibit inertia. For instance, it would be interesting to know how is the outcome of the political equilibrium affected by time lags in the adjustment of the strength of the social norm.

\section{THE MODEL}

There is a continuum of individuals. All individuals are a priori identical in every aspect except their valuation of leisure. ${ }^{2}$ To highlight the incentives to draw on social insurance benefits we assume that individuals face a binary choice of whether to look

\footnotetext{
${ }^{1}$ There has been a vivid discussion on whether peoples attitudes toward social insurance and redistribution differ depending on whether poverty is a result of bad luck or low effort. These groups are often referred to as "deserving" and "undeserving" poor respectively. Bowles and Gintis (2000) argue that individuals, for reasons of reciprocity, are more willing to support poor of the first category than the second. Bowles, Fong and Gintis (2001) have found empirical support for this hypotesis based on both experimental data and opinion polls on attitudes towards redistribution. Similar conlusions are reached in a study by Fong (2001) based on opinion polls.

${ }^{2}$ In their analysis of welfare stigma, Besely and Coate (1992) assume that the valuation of leisure varies across individuals. However, unlike here, they are not concerned with political equilibrium, they rule out the possibility of multiple equilibria, and do not focus on dynamic aspects.
} 
for a job or to live off social security benefits. Those who look for a job face a fixed and given risk $\rho$ of becoming unemployed. By thus assuming that the unemployment risk is exogenous, we in effect assume that each individual's choice of his or her probability of being employed is restricted to two values, $1-\rho$ for those who decide to look for a job, and zero for those who decide to live off the government benefit. (Lindbeck and Nyberg, 2001, develop a model where the employment probability is instead chosen from a continuum.). Let $x$ be the non-employment rate in the economy, the "benefit rate" for short. The beneficiaries belong to two distinct categories in this model: those who exert effort to look for a job, but do not succeed or lose their jobs (the "deserving" beneficiaries), and those who do not look for a job (the "undeserving" beneficiaries). Those who do not look for a job suffer a disutility (or stigma) by deviating from the norm. As in LNW, we assume that the disutility is smaller if more people live off the transfer. The strength of the social norm thus depends on the benefit rate $x{ }^{3}$ The absence of a social norm, as in traditional economic analyses, will appear as a special case.

Let $w>0$ be the going wage rate in a perfectly competitive labour market, that is, $w$ is the constant marginal productivity of every employed worker. Those who do not work receive a per-capita lump-sum transfer $T>0$ from the government. Let $\tau \in(0,1)$ be the tax rate on labour income used to finance the lump-sum transfer payments. The real wage is normalized to unity. The preferences of individuals are assumed to be represented by

$$
u= \begin{cases}(1-\rho)[\alpha \ln (1-\tau)-\beta]+\rho \alpha \ln T & \text { if looking for a job } \\ \alpha \ln T-\gamma & \text { otherwise }\end{cases}
$$

where $\alpha>0,-\infty<\beta<+\infty, \gamma \geq 0$ and $0<\rho<1$. Here $\alpha$ is the utility weight placed on consumption, $\beta$ the weight on leisure, a weight which varies between individuals (negative for those who prefer to work even in the absence of economic and social incentives to do so), and $\gamma$ is the weight placed on norm adherence. ${ }^{4}$ The population distribution of the parameter $\beta$ is given by a cumulative distribution function $\Phi$ with positive density on the whole real line.

All individuals simultaneously choose whether to look for a job or not. When an individual makes this decision, he or she treats the tax rate $\tau$, transfer $T$ and the fraction $x$ of beneficiaries as exogenous. Since the distribution $\Phi$ of leisure valuations has full support, there exists a critical valuation of leisure $\beta^{*}$, such that individuals

\footnotetext{
${ }^{3}$ This formulation allows for the possibility that the stigma depends only on the fraction of the population $z$ of "undeserving" welfare recipients, granted the unemployment rate $\rho$ is known by the individuals.

${ }^{4}$ This specification can be shown to be consistent with Cobb-Douglas preferences over consumption, leisure and norm adherence.
} 
with lower (higher) leisure valuations strictly prefer to (not) look for a job. This parameter value - determined from indifference in $(1)$ - is

$$
\beta^{*}=\alpha \ln \left(\frac{1-\tau}{T}\right)+\frac{\gamma}{1-\rho} .
$$

The population share of individuals who look for a job thus equals $\Phi\left(\beta^{*}\right)$. In view of the size of the population - here treated as a continuum - we assume that the resulting population share of employed with probability one equals the expected share, $(1-\rho) \Phi\left(\beta^{*}\right)$. Hence:

$$
x=1-(1-\rho) \Phi\left(\beta^{*}\right) .
$$

The utility weight $\gamma$ attached to norm adherence is assumed to depend on current or past population shares of transfer recipients. We study two polar cases. In the first, $\gamma$ depends only on the current population share of transfer recipients: $\gamma=g(x)$ for some function $g$. We refer to this case as instantaneous stigma. In the second case, there is a lag in the stigma. In this lagged stigma case, there is a sequence of election periods in which the tax rate and per-capita transfer are determined, and the current stigma depends only on the population share of transfer recipients in the preceding period: $\gamma_{t}=h\left(x_{t-1}\right)$ for some function $h$. We study political equilibrium in each of these two model specifications.

\section{InSTANTANEOUS STIGMA}

In the case of instantaneous stigma, the utility weight attached to norm adherence is endogenous and instantaneous, given by $\gamma=g(x)$, where $g:[0,1] \rightarrow \mathbb{R}_{+}$is continuously differentiable with $g^{\prime} \leq 0$. Note that this makes the critical valuation of leisure $\beta^{*}$, defined in (2), a function of $x$. A profile of individual choices - whether or not to look for a job - thus constitutes a Nash equilibrium if and only if the resulting share $x$ of transfer recipients satisfies the fixed-point equation

$$
x=F(x),
$$

where $F:[0,1] \rightarrow[0,1]$ is defined by $(3)$ as $F(x)=1-(1-\rho) \Phi\left[\beta^{*}(x)\right]$. We note that, given $\tau<1$ and $T>0$, the function $F$ is continuous. Therefore, it has at least one fixed point for any given policy $(\tau, T)$. Moreover, since $F$ is non-decreasing, there is a priori a possibility of multiple equilibria. ${ }^{5}$ In sum: to every combination of tax-rate $\tau$ and per-capita transfer $T$ there exists at least one Nash equilibrium.

\footnotetext{
${ }^{5}$ A similar fixed-point equation was used in Lindbeck, Nyberg and Weibull (1999).
} 
Some or all of the Nash equilibria associated with a given policy $(\tau, T)$ may result in a budget surplus or deficit. In this simple model, the government budget is balanced if $(1-x) \tau=T x$, or, equivalently, iff

$$
x=\frac{\tau}{\tau+T} .
$$

We refer to a tax-transfer pair $(\tau, T)$ as a balanced policy if equation (5) is met for some $x$ satisfying equation (4). Hence, $(\tau, T) \in P=(0,1) \times(0,+\infty)$ is a balanced policy if and only if

$$
\frac{T}{\tau+T}=(1-\rho) \Phi\left[\alpha \ln \left(\frac{1-\tau}{T}\right)+\frac{1}{1-\rho} g\left(\frac{\tau}{\tau+T}\right)\right] .
$$

This equation defines the subset $P_{0} \subset P$ of balanced policies. It is easily verified that for every $\tau$ there exists at least one $T$ such that $(\tau, T) \in P_{0}$. The set $P_{0}$ of balanced policies defines a Laffer curve reflecting the influence of both economic incentives and social norms.

What policy will emerge in this economy? We call a balanced policy a political equilibrium policy (or an unbeatable policy) if no other balanced policy can defeat it by strict majority in a binary vote. We focus on the voting scenario in which all individuals know their own "type" $\beta$, and voting takes place before they decide whether or not to look for a job.

For the purpose of analyzing voting decisions, we identify the expected utility $U_{\beta}(\tau, T)$ for an individual of type $\beta$ under any balanced policy $(\tau, T)$. This is obtained directly from equations (1) and (5):

$$
U_{\beta}(\tau, T)=\max \left\{(1-\rho)(\alpha \ln (1-\tau)-\beta)+\rho \alpha \ln T, \alpha \ln T-g\left(\frac{\tau}{\tau+T}\right)\right\} .
$$

In other words, if an individual of type $\beta$ considers some balanced-budget policy, $(\tau, T)$ - proposed, for instance, by a political candidate - then this individual expects the population share of transfer recipients to be $x=\tau /(\tau+T)$, by equation (5). In this anticipated Nash equilibrium, the individual will choose the better of the two alternatives available, that is, to look for a job or to live off the transfer. The corresponding expected utility levels are then given by the first and second elements of the set on the right hand side. The ex ante expected utility to the individual of type $\beta$ is thus expressed by equation (7).

It is straightforward to show that, like in the median-voter theorem, a policy is a political equilibrium policy if and only if it is an ideal policy for the individual with the median valuation of leisure - a policy which maximizes that individual's expected utility as defined in equation (7). ${ }^{6}$

\footnotetext{
${ }^{6}$ Consider an individual whose leisure parameter $\beta$ is the median of the distribution $\Phi$, and
} 
3.1. Example. Suppose $g(x)=\exp \left[-(x / a)^{b}\right]$ for $a>0$ and $b>1$, and suppose $\Phi(z)=(1+\exp [-c(z-d)])^{-1}$ for $c, d>0$. The median $\beta_{m}$ of $\Phi$ thus is $\beta_{m}=d$. Figures 1a and $1 \mathrm{~b}$ depict the set $P_{0}$ of balanced policies - the Laffer curve - in two cases (for $a=0.3, b=5, c=3, d=0.5, \rho=0.2$, and $a=0.3, b=10, c=3$, $d=0.1, \rho=0.2$, respectively). As one follows the Laffer curve from a low tax rate to higher rates, the share of beneficiaries first increases slowly because of the strong work norm. However, as this share approaches about 20 percent of the population, the norm begins to erode strongly, whereupon the Laffer curve folds and lands on a lower level. For tax rates in this latter interval there exist three equilibria, with the equilibrium with the highest per-capita transfer corresponding to the lowest share of transfer recipients - and the strongest work norm. In Figure $1 \mathrm{~b}$ the work norm has been given a greater utility weight, and is more sensitive to changes in the number of beneficiaries than in the case depicted in 1a.

The graphs also show indifference curves for the median individual. The nonmonotonic shape of these curves reflects that the median individual either participates in the labour market (the upward sloping segments to the left in the graphs) or chooses to be a beneficiary (the segments to the right in the graphs). The curve that is tangent to the Laffer curve corresponds to the highest expected utility achievable under any balanced-budget policy. In the political equilibrium policy in Figure 1a, the tax rate is about $12 \%$ and the benefit about 0.42 . (Recall that the gross wage rate is normalized to 1.) In Figure 1b the corresponding numbers are approximately $17 \%$ and 0.63 . The graphs illustrate that when work norms are strong, benefits can be raised considerably with only a modest increase in the tax rate.

[Figures 1a and 1b about here]

\section{LAGGED STIGMA}

In the preceding section, we assumed that the intensity of the social norm adjusts instantaneously to the population share of beneficiaries. However, adjustments in the intensity of social norms are likely to exhibit some inertia. This might tempt people to vote for higher benefits than when the intensity adjusts instantaneously. Under such inertia, relatively high transfers can be supported by modest tax rates in the short run. Political equilibrium in the short run may, however, lead to subsequent changes in the intensity of social norms. This suggests the possibility of a sequence of short-term equilibria. It also raises the question of whether there exist long-term steady-states for such sequences temporary political equilibria.

let $\left(\tau_{m}, T_{m}\right)$ be an ideal policy for this individual. It is straightforward to show that this policy is unbeatable under majority rule, and that if $\left(\tau^{\prime}, T^{\prime}\right)$ is a political equilibrium policy, then it must be an ideal policy for the median individual. 
Consider a sequence of discrete time periods $t$, where the tax rate $\tau_{t}$ and transfer $T_{t}$ are determined at the outset of each period by way of majority vote. We assume that the stigma in the current period depends on the population share of transfer recipients in the preceding period, $x_{t-1}$, that is, $\gamma_{t}=h\left(x_{t-1}\right)$ for some function $h{ }^{7}$ Hence, the utility weight attached to norm adherence is now exogenous in each period - "inherited" from the equilibrium outcome in the preceding period. One interpretation is that while each generation's perception of the work norm is constant over time the norm may change as new generations enter. ${ }^{8}$ We assume that $h$ has the same qualitative properties as $g$. Suppose, for simplicity, that all other parameters are the same in all periods.

In the lagged model, a profile of individual choices constitutes a Nash equilibrium in period $t$ if and only if the resulting population share $x_{t}$ satisfies $x_{t}=$ $1-(1-\rho) \Phi\left[\alpha \ln \left[\left(1-\tau_{t}\right) / T_{t}\right]+\gamma_{t} /(1-\rho)\right]$ where $\gamma_{t}$ is a constant in period $t$. As in the preceding section, budget balance requires that $x_{t}=\tau_{t} /\left(\tau_{t}+T_{t}\right)$. Hence, we refer to a tax-transfer pair as a balanced policy in period $t$ if

$$
\frac{\tau_{t}}{\tau_{t}+T_{t}}=1-(1-\rho) \Phi\left[\alpha \ln \frac{1-\tau_{t}}{T_{t}}+\frac{h\left(x_{t-1}\right)}{1-\rho}\right] .
$$

This condition defines the set $P_{t}\left(x_{t-1}\right) \subset P$ of balanced policies in period $t$, conditional on the share $x_{t-1}$ of transfer recipients in the preceding period . Again, we conclude that for every tax-rate $\tau_{t} \in(0,1)$ there exists at least one $T_{t}$ such that $\left(\tau_{t}, T_{t}\right) \in P_{t}\left(x_{t-1}\right)$. Generically, this "lagged Laffer curve" coincides with the "instantaneous Laffer curve" at only three points: at the boundary points where $\tau_{t} \rightarrow 0$ and $\rightarrow 1$, respectively, and at the tax rate in the preceding period, that is, when $\tau_{t}=\tau_{t-1} \cdot{ }^{9}$ Note that the lagged Laffer curve at this point is steeper than the instantaneous Laffer curve. Assuming continuous differentiability, this follows straightforwardly from implicit differentiation of conditions (6) and (8).

In the same spirit as before, we call a balanced policy $\left(\tau_{t}, T_{t}\right)$ a political equilibrium policy, given the share of transfer recipients in the preceding period, if no other balanced policy can defeat it in a binary majority vote. The expected utility for an individual of type $\beta$ under any balanced policy $(\tau, T)$ in period $t$, given $x_{t-1}$, is

$$
V_{\beta}\left(\tau, T, x_{t-1}\right)=\max \left\{(1-\rho)(\alpha \ln (1-\tau)-\beta)+\rho \alpha \ln T, \alpha \ln T-h\left(x_{t-1}\right)\right\} .
$$

\footnotetext{
${ }^{7}$ In this respect, the lagged version of our model is similar to LNW section VII, and to the model in Kandori (2002), where there is a disutility associated with deviating from the median effort level of others in the preceding period.

${ }^{8}$ This could be perceived as a sequence of overlapping generations, where each generation lives for two periods, as "children" in the first period, and as voters and workers in the second. The assumed lag would simply mean that preferences are completely formed during childhood.

${ }^{9}$ If $\tau_{t}=\tau_{t-1}$, then we may set $T_{t}=T_{t-1}$, in which case budget balance requires $x_{t}=x_{t-1}$.
} 
Clearly, also with a lagged stigma, a policy is a political equilibrium if and only if it is an ideal policy for the individual with the median valuation of leisure. ${ }^{10}$ This definition of political equilibrium is a short-term concept in the sense that it treats the stigma - the disutility of defecting from the work norm - as a constant, while this may change from period to period.

This raises the question of a steady-state, or stationary, political equilibrium in the lagged model, that is, a political equilibrium such that next period's stigma will be the same as in the current period. Following LNW (section VII), we define a long-run political equilibrium in the lagged model as a political equilibrium $\left(\tau_{t}, T_{t}\right)$ in the lagged model, given $x_{t-1}$, such that $h\left(x_{t}\right)=h\left(x_{t-1}\right)$. If $h$ is strictly decreasing, this requires $x_{t}=x_{t-1}$, that is, the policy has to be a balanced policy also in the model with instantaneous stigma. At such a point the instantaneous Laffer curve intersects the lagged Laffer curve, and the median individual's maximal indifference curve is tangential to the latter.

4.1. Example. Consider the same parametric specification as in Figure 1a (including $h=g$ ). Moreover, suppose that the policy in the preceding period was the political equilibrium policy in that example: $\tau_{t-1} \approx 0.12, T_{t-1} \approx 0.42$, and hence $x_{t-1} \approx 0.22$. Figure 2 a shows a close-up of Figure 1 a around this point. The dashed curve through this point is a segment of the lagged Laffer curve. The graph also contains indifference curves of the median individual. As expected, the political equilibrium policy in period $t$ in the lagged model, represented by the tangency between the lagged Laffer curve and the dashed indifference curve, results in more generous transfers than when the stigma adjusts instantaneously. With a constant stigma, a given increase in benefits leads to a smaller increase in the number of beneficiaries.

Figure $2 \mathrm{~b}$ depicts the long-run equilibrium where the indifference curve is tangent the lagged Laffer curve where it intersects the instantaneous Laffer curve. At this point, both the tax rate and the benefit level are higher than in the equilibrium with instantaneous adjustment of the norm.

[Figures $2 \mathrm{a}$ and $2 \mathrm{~b}$ about here]

Now, consider the effect of a small macroeconomic shock. Specifically, suppose the unemployment risk $\rho$ increases by 3 percentage points in the example in Figure $1 \mathrm{~b}$ (where the norm is highly sensitive to the number of beneficiaries). As can be seen from the instantaneous Laffer curve in Figure 3a, the scope for providing generous benefits is considerably reduced by the shock (c.f. Figure $1 \mathrm{~b}$ ). The political equilibrium policy after the shock and with instantaneous norm adjustment is $\tau \approx 0.17$ and $T \approx 0.48$. It can be shown that the political equilibrium in the lagged version

\footnotetext{
${ }^{10}$ Here this is a policy which maximizes that individual's expected utility, defined as in equation (7), but now with $g(\tau /(\tau+T))$ replaced by $h\left(x_{t-1}\right)$.
} 
of the example in Figure 1b is close to the instantaneous political equilibrium. The reason is that the lagged Laffer curve almost coincides with the instantaneous Laffer curve at that point, since norm adherence is almost complete. This is, however, not the case after the shock in $\rho$. Figure 3b shows that if we start at the policy which is the political equilibrium with instantaneous adjustment, then next period's political equilibrium in the lagged model would involve a higher tax rate and benefit level. But this is only the first step in a dynamic adjustment process in a sequence of election periods. As illustrated by the dotted path in Figure 3c, tracing out a sequence tangency points between lagged Laffer curves and indifference curves of the median individual, this process converges to a political equilibrium far from the instantaneous political equilibrium. In this steady-state equilibrium of the lagged model, $\tau \approx 0.15$ and $T \approx 0.2$, and hence $x_{t-1} \approx 0.43$. At that point, the influence of the norm has basically disappeared, and, as a result, the lagged and instantaneous Laffer curves approximately coincide.

[Figures $3 \mathrm{a}, 3 \mathrm{~b}$ and $3 \mathrm{c}$ about here]

Suppose now that the unemployment risk $\rho$ returns to the pre-shock level. The lagged Laffer curve, conditional on the inherited population share $x_{t-1} \approx 0.43$ of beneficiaries, coincides with the segment of the Laffer curve in Figure 1b where work norms have no influence. The lagged political equilibrium then occurs at the tangency point between this curve and the median individual's indifference curve. In this sense, the model exhibits hysteresis. ${ }^{11}$

\section{Concluding Remark}

We have shown how social norms against living off handouts from the government may mitigate free riding on income-insurance systems. Our analysis assumes rational expectations, including the assumption that a possible time lag in the social norm is correctly anticipated. It would be worth analysing the case when individuals do not fully understand the dynamics of norm formation (for a heuristic discussion of this issue, see Section VII in Lindbeck, Nyberg and Weibull, 1999).

\footnotetext{
${ }^{11}$ Kandori (2002) also derives hysteresis properties in a model where work norms and economic incentives interact. However, the dynamic in that paper differs from that in this paper. In Kandori's model, a sequence of stochastic shocks to individual choices probabilistically results in a reduction in effort over time.
} 


\section{REFERENCES}

Besley, T., Coate, S., 1992. Understanding Welfare Stigma: Taxpayer Resentment and Statistical Discrimination, Journal of Public Economics 48, 165-183.

Bowles, S., Gintis, H., 2000. Reciprocity, Self-Interest and the Welfare State, The Nordic Journal of Political Economy 26, 35-53.

Fong, C., 2001. Social Preferences, Self-Interest and the Demand for Redistribution, Journal of Public Economics 82, 225-246.

Kandori, M., 2002. The Erosion and Sustainability of Norms and Morale, Discussion Paper CIRJE-F-169, University of Tokyo, September.

Lindbeck, A., Nyberg, S., 2001. Raising Children to Work Hard - Altruism, Work Norms and Social Insurance, Working Papers in Economics 2001:5, Department of Economics, Stockholm University.

Lindbeck, A., Nyberg S., Weibull, J.W., 1999. Social Norms and Economic Incentives in the Welfare State, Quarterly Journal of Economics 114, 1-35. 

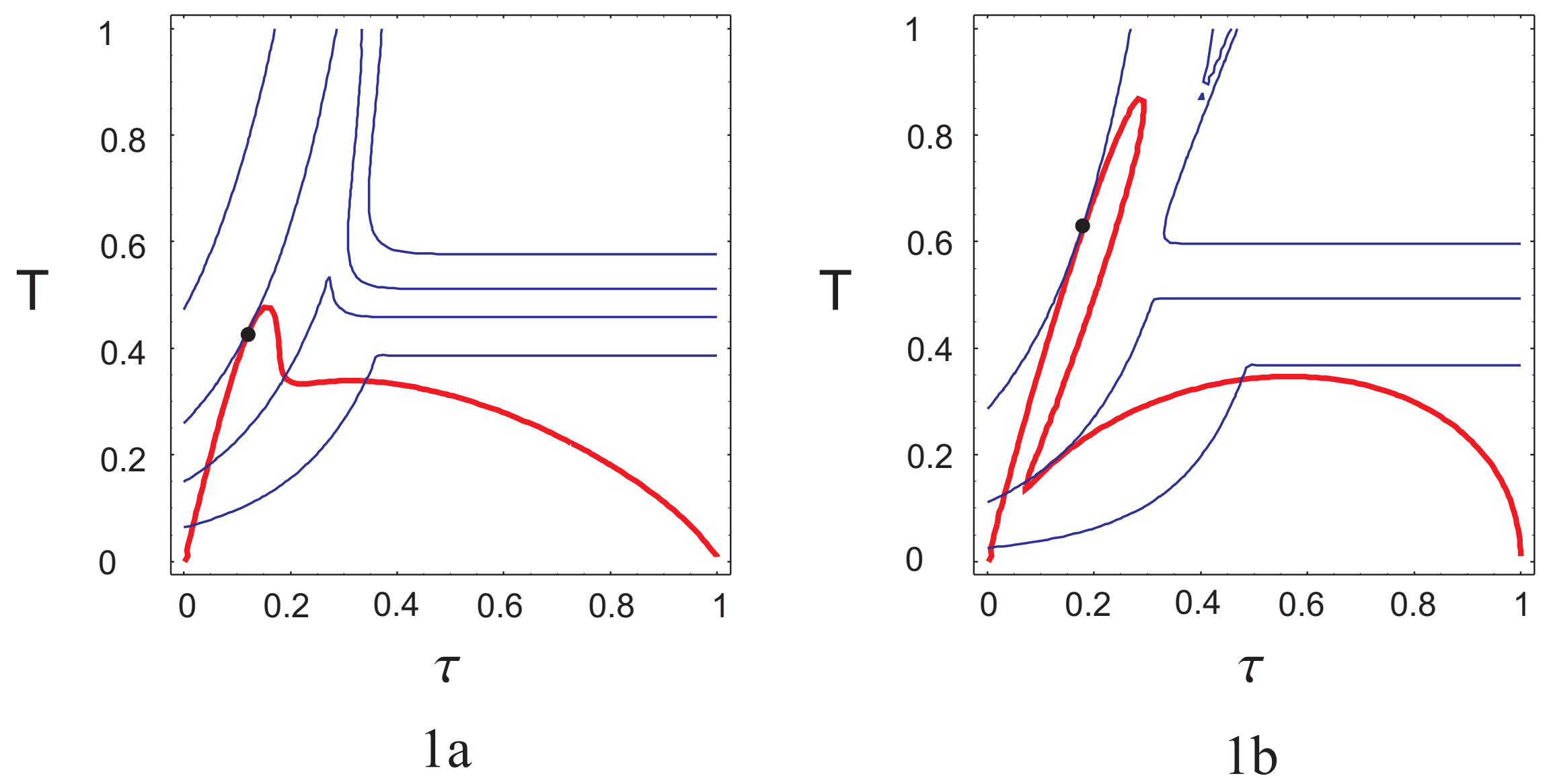

Figure 1: Political equilibria with instantaneous norm adjustment. 

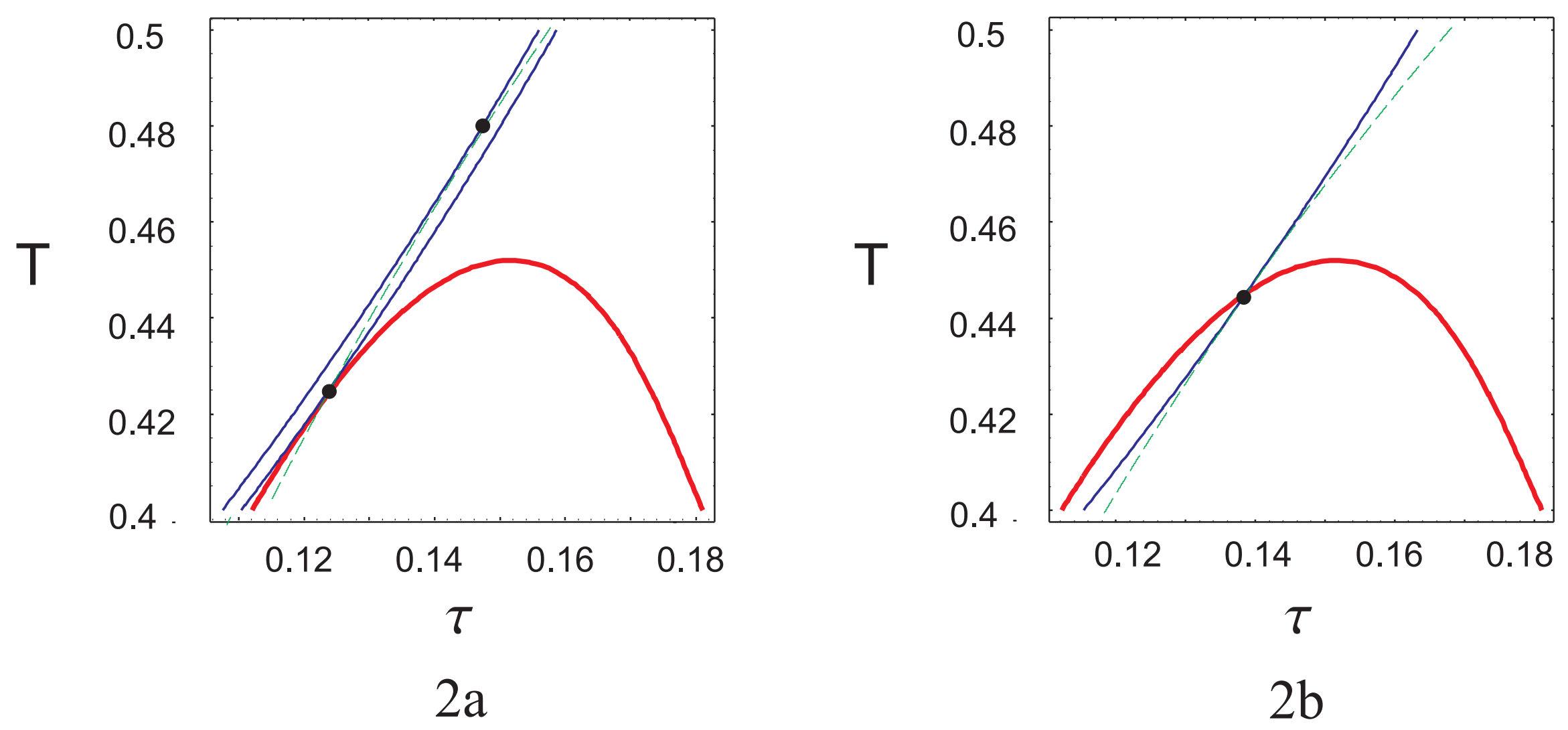

Figure 2: Short-run (2a) and long-run (2b) political equilibria with lagged norm adjustment. 

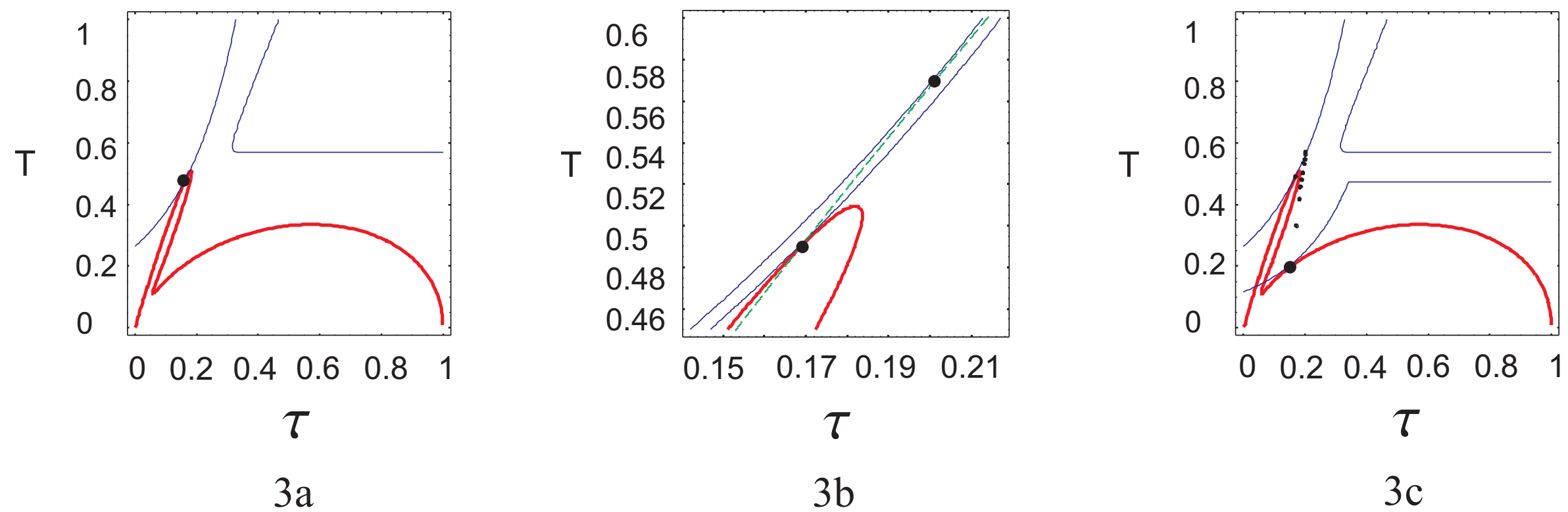

Figure 3: Short-run and long-run political equilibria after an unemployment shock. 